\title{
A técnica da escultura em madeira com máscara de chumbo policromada: a con- tingência dos Cristos da Paixão da Ordem Terceira do Carmo de Ouro Preto (MG)
}

\author{
LIA SIPAÚBA PROENÇA BRUSADIN \\ MARIA REGINA EMERY QUITES
}

\section{Resumo}

Este estudo tem como objetivo analisar as técnicas e materiais das esculturas da Paixão de Cristo, localizadas nos retábulos laterais da nave e do consistório da Igreja da Ordem Terceira de Nossa Senhora do Carmo de Ouro Preto, Minas Gerais. Enfatizou-se a tecnologia da escultura em madeira com máscara de chumbo policromada, comum na Espanha e países andinos nos séculos XVII e XVIII, é rara em Minas Gerais. A metodologia aplicada foi o levantamento

Palavras-chave: Escultura policromada em madeira, máscara de chumbo, Ordem Terceira de Nossa Senhora do Carmo de Ouro Preto bibliográfico nas áreas de história, arte; investigação in loco e registro fotográfico dos Cristos da Paixão. Tais imagens devem ser preservadas e reconhecidas como importante fonte de pesquisa histórica, artística e social. 


\title{
The technique of sculpture in wood with polychrome lead mask: the contingency of Christs of Passion of Third Order of Carmen of Ouro Preto (MG)
}

\author{
LIA SIPAÚBA PROENÇA BRUSADIN \\ MARIA REGINA EMERY QUITES
}

\begin{abstract}
This study aims to analyze the techniques and materials of sculptures of the Passion of Christ, located in the lateral altarpieces of the ship and of the consistory of the Church of Third Order of Our Lady of Carmen of Ouro Preto (MG). It was emphasized the technology of wood carving with polychrome lead mask, common in Spain and Andean countries in the 17th and 18th centuries, which is rare in Minas Gerais. The methodology used was the bibliographic survey in the areas of history, art; in situ research and photographic record of Christs Passion. Such images must be preserved and recognized as an important source of historical, artistic and social research.
\end{abstract}

Keywords:

Polychrome sculpture in wood, lead mask, Third Order of Our Lady of Carmen of Ouro Preto 


\section{La técnica de esculturas en madera con máscara de plomo policromado: la contin- gencia de los Cristos de la Pasión de la or- den Tercera de Carmo de Ouro Preto (MG)}

\section{LIA SIPAÚBA PROENÇA BRUSADIN MARIA REGINA EMERY QUITES}

\section{Resumen}

Este estudio tiene el objetivo de analizar las técnicas y materiales de las esculturas de la Pasión de Cristo, localizadas en los retablos laterales de la nave y del consistorio de la Iglesia de la Orden Tercera de Nossa Senhora do Carmo de Ouro Preto, Minas Gerais. Se dio destaque a la tecnología de la escultura en madera con máscara de plomo policromado, común en España y en países andinos en los siglos XVII y XVIII, es rara en Minas Gerais. La metodología aplicada fue la investigación

Palabras-clave: Escultura policromada en madera, máscara de plomo, Orden Tercera de Nossa Senhora do Carmo de Ouro Preto bibliográfica en las áreas de historia, arte; investigación in loco y registros fotográficos de los Cristos de la Pasión. Esas imágenes deben ser preservadas y reconocidas como una fuente importante de investigación histórica, artística y social. 


\section{Introdução}

Durante o século XVIII e inícios do século XIX, no Brasil colônia, a região das Minas Gerais teve a religião cristã amparada por suas imagens de devoção. A imaginária devocional luso-brasileira fez parte do desejo de um realismo visual e foi elemento significativo para os fundamentos de uma cultura e mentalidade barrocas. Geralmente, as esculturas eram importadas do Reino para posteriormente serem feitas na própria colônia, haja vista que a utilização de imagens para o culto religioso resultou ao escultor imaginário um alcance a um grande nível técnico de produção e estética durante o século XVIII. Consequentemente, a imaginária sagrada apresentou uma grande variedade de técnicas e materiais.

No presente artigo foi realizada a investigação da técnica da escultura em madeira com máscara de chumbo policromadas das esculturas da Paixão de Cristo localizadas nos retábulos da nave e retábulo do consistório da Igreja da Ordem Terceira de Nossa Senhora do Carmo de Ouro Preto, Minas Gerais. Dessa maneira, a metodologia aplicada embasou-se na pesquisa histórica e da história da arte, bem como na averiguação in loco e registro fotográfico das imagens, para saber de onde e em que época essa técnica foi empregada, qual era forma de sua concepção e como ela foi feita em tais esculturas. Além disso, procuramos referência sobre uma imaginária de chumbo em Minas Gerais, especialmente na cidade de Ouro Preto, e algum apontamento a essas em outras regiões do Brasil, no transcorrer do século XVIII e XIX. Também pesquisamos sobre as primeiras casas de fundição na Capitania de Minas, local com forjas e instrumentos específicos para fundir metal.

Logo, a técnica construtiva desse conjunto escultórico se caracteriza por todas as esculturas dos Cristos da Paixão ser em 
madeira policromada e ter somente a face feita em um mesmo molde com chumbo e policromia. Tal técnica da escultura de madeira e chumbo foi frequente na imaginária do século XVII, sobretudo do século XVIII, na Espanha, a qual foi posteriormente exportada aos países latinos, em especial na região dos Andes. Essa técnica consistia na colocação de uma máscara feita de chumbo, encaixada ao crânio de madeira, definindo a fisionomia da imagem, tendo também a função de fixar os olhos de vidro. O uso desta técnica foi raro em Minas Gerais, e é citada como mascarillas em referências latino-americanas.

Assim sendo, propomo-nos em estudar os dados existentes sobre cada obra escultórica como fonte direta, à medida que a investigação de esculturas policromadas em madeira compõe um campo interdisciplinar imprescindível para a construção científica e suas áreas de atuação profissional. Esse tipo de estudo ajuda na compreensão e preservação do patrimônio brasileiro. A partir da investigação histórica e artística da técnica da escultura em madeira com máscara de chumbo policromadas, encontramos dados que suprem algumas lacunas a respeito das imagens dos Cristos da Paixão.

\section{A técnica da escultura em madeira com máscaras de chumbo policromadas: a escola de Quito de imaginária}

As imagens dos Cristos da Paixão se evidenciam por serem esculturas policromadas em madeira. A escultura policromada é recoberta por policromia e se caracteriza por ser ornamentada com douramentos e cores variadas, cujo suporte e policromia formam um todo indissociável; são compostas, dessa maneira, por forma e cor (SERCK-DEWAIDE, 2005). Nesse sentido, conforme Quites (1997), na concepção de uma escultura policromada em madeira, não pode ser separada a talha da policromia, pois ambas formam um conjunto indissociável. Se uma escultura foi concebida com policromia, este é um dado essencial para a sua compreensão, assim, a escultura policromada é a união da escultura com a pintura, geralmente é feita por um escultor e um policromador e/ou pintor.

Os materiais e técnicas empregados na escultura policromada em madeira no Brasil colônia são de grande heterogeneidade. A arte barroca dessa época se utilizou de artifícios engenhosos para impressionar e comover os fiéis. As características, qualidades artísticas e tecnológicas do acervo escul- 
tórico da região das Minas Gerais do século XVIII e século XIX são precedentes de proveitosas pesquisas em diversificados ramos e aspectos do conhecimento.

Não obstante, buscamos por um referencial nacional e internacional relacionado à técnica da máscara de chumbo, sobre a qual, internacionalmente, encontramos somente menção em estudos acadêmicos a propósito da Escola de Quito de Imaginária, no Equador; e no Brasil, alguns estudos que se remetem aos Cristos da Paixão do Carmo de Ouro Preto. Enquanto referência internacional trazemos, primeiramente, o trabalho de Gallegos Danoso (1994) sobre o desenvolvimento dessa Escola de Quito de Imaginária, que fala da tradição espanhola, do século XVII e XVIII no uso da máscara, ou mascarilla, e sua função de modelar as feições iconográficas e fixar os olhos de vidro.

Como herança de Sevilha e da Andaluzia do século XVII e, ao longo do XVIII, foi uma característica generalizada a fabricação de máscaras de chumbo definindo exatamente as fisionomias conforme era exigida pela iconografia. Uma jovem mulher com plena vitalidade para a Virgem Maria, uma mulher madura com bochechas marcantes para Santa Ana, um jovem imberbe para Santo Antonio de Pádua, o calvo de barba curta para São Pedro, o velho de barba comprida para São Francisco de Paula etc. A máscara permitia, além disso, que no interior fossem colocados os olhos de vidro fundidos e coloridos, cujo resultado era um olhar claro e transparente' (GALLEGOS DE DANOSO, 1994, p. 7, tradução nossa).

Assim, cada escultura teria exatamente a mesma feição, ou seja, representaria o mesmo personagem religioso no teatro sacro barroco, no caso do nosso objeto de estudo, a figura de Jesus Cristo. Para compreendermos a aplicação da técnica da máscara de chumbo policromada na imaginária de Quito, é necessário recorrermos também às questões da natureza da sua produção mercantil e a história da criação dos órgãos gestores desse setor.

Temos os estudos de Kennedy-Troya (1998), sobre as artes de Quito no período colonial, em que trata da criação da Real Audiência e Presidência de Quito. Tal instituição teve lugar somente 29 anos depois de sua fundação, em 29 de agosto de 1563, e era subordinada ao vice-reinado do Peru (Equador, norte do Peru, sul da Colômbia, e norte do Brasil). Cumpria estritamente funções como tribunal de justiça e também tarefas governativas de jurisdição política, militar e religiosa. Foi encerrada em 1822, com a adesão dessa área à Gran-Colômbia, criada em 1819. 
Durante o século XVI e até aproximadamente a metade do século seguinte, a Audiência de Quito foi parte de um vasto espaço econômico por meio da divisão geográfica da produção mercantil. Posteriormente, Equador, Chile, Argentina e Paraguai. Sempat Assadourian descreveu a região daquele período como espaço peruano, fundamentada na economia da mineração² (KENNEDY-TROYA, 1998, p. 91, tradução nossa).

Conquanto, a partir do século XVI, a Real Audiência de Quito estabelecia os circuitos comercias de mercadorias, e, dentre estes, o das obras de arte sacra. Segundo a autora, durante a segunda metade do século XVIII, Quito seguia produzindo escultura e pintura barroca em grande quantidade e a baixos preços. As lojas e oficinas de artesãos e artistas vendiam obras completas ou por peças. Era comum a exportação de séries pictóricas hagiográficas e esculturas de menino Jesus, crucifixos, calvários, anjos, entre outras. A produção artística e artesanal de Quito teve como importante aspecto a grande demanda da América Latina, ocorreu o surgimento do que autora denominou de "lojas-oficinas" em Quito e de uma produção barroca em série.

É assim a linguagem barroco quiteño que se internacionalizou durante esses anos. Devido à grande demanda teve que se "industrializar", si se encaixa esse termo. O estereótipo das suas formas e a repetição do conteúdo foram uma consequência lógica deste fenômeno; um fenômeno que acarretaria no estabelecimento do que chamamos "atalhos" nos processos produtivos, como veremos mais adiante? . (KENNEDY-TROYA, 2009, p. 75, tradução nossa).

Com essa internacionalização do barroco em Quito nos no século XVIII e com a ampla demanda por obras de arte, ocorreu certa "industrialização", que na verdade foi uma estereotipação das formas, que a autora chamou de "atalhos" da manipulação dos processos produtivos para o abastecimento da exportação. Isso não foi uma industrialização no termo moderno, ou seja, da utilização de máquinas, mas uma produção seriada de forma que encurtasse o tempo de produção e que resultasse em uma maior quantidade de obras.

Vallin (1987) também menciona essa "industrialização" em meados do século XVIII. O pesquisador estudou as técnicas empregadas pelos artífices do período colonial nos países latinos de língua espanhola, cujos artistas empregavam técni- 
cas europeias e utilizaram de madeiras e materiais equivalentes aos usados na Europa. Para o autor, a técnica da máscara de chumbo foi uma espécie de "industrialização": "Também se apelou para a "industrialização" quando as esculturas eram concluídas com máscaras e mãos feitas de chumbo e foram confeccionadas esculturas completas com esse material4" (VALLIN, 1987, p. 1, tradução nossa). Kennedy-Troya (1998), igualmente cita ser a técnica da máscara de chumbo policromada de origem europeia, mas que fora adaptada e reelaborada na colônia espanhola para a demanda interna e exportação.

É possível que elementos tais como máscaras de chumbo, utilizados na preparação de faces, as urnas de vidro, igualmente as esferas dos olhos de vidro, foram importados da Europa e reformulados ou decorados para uso interno e de exportação de produtos $^{5}$ (KENNEDY-TROYA, 1998, p. 94, tradução nossa).

Nesse sentido, no século XVIII, a reivindicação por obras de arte em Quito foi tão grande que, segundo Kennedy-Troya (2002), aconteceu uma exportação de esculturas "inteiras" ou "por peças", isto é, a saída de partes que completariam uma imagem, como: cabeças, mãos e pés; prática muito comum em diversos países. Eram peças que seriam montadas/ensambladas, no seu lugar de destino, em especial constituiriam imagens de vestir e roca. Com isso, os artistas criaram os "atalhos", o uso sistemático de mascarillas de chumbo, admiravelmente policromadas, foi um deles. Esta técnica evitava o árduo e pesado trabalho na talha de madeira. A autora aborda igualmente que tal técnica modelava a fisionomia e ajudava a segurar os olhos de vidro fundido.

No entanto, a grande maioria ia por partes: cabeças com sua máscara de chumbo, algumas eram de estanho, ou faces de marfim-vegetal, as mãos e em certas ocasiões os pés - base, tudo policromado; eram peças soltas prontas para serem montadas e vestidas, peças que constituíam as partes fundamentais das peças de roca. Para aliviar o peso, ou para reduzir o em espaço o porão de um navio ou para reduzir custos, evitando o entalhe total da imagem, deu origem a uma modalidade de ordenação que deu destaque às imagens Quito [...] O artista de Quito e sua oficina tiveram que se adaptar a todas essas ordens. Tendo em vista a demanda externa e a crise econômica vivida pela Audiência, o artista teve que criar os chamados atalhos na produção: o uso sistemático de másca- 
ras de chumbo encarnadas - adaptadas para Santos e virgens, crianças ou anjos, nunca de Cristos -, a incorporação do vidro fundido em moldes pintados por trás dos olhos, a cabeça somente pintada e sem entalhe, na qual poderia ser colocada uma cabeleira natural, modelos exclusivos para o entalhe das mãos e dos pés soltos ${ }^{6}$ [...] (KENNEDY-TROYA, 2002, p. 192 - 193, tradução nossa).

De acordo com o Guia Unificado dos Museus de Quito, elaborado por Morán Proaño (ANO), para a confecção das esculturas devocionais em Quito, a madeira foi material mais utilizado seguindo a tradição espanhola e os modelos da escola da região da Andaluzia e Castela. A principal característica das esculturas, no último terço do século XVII - XVIII, foi a técnica das mascarillas metálicas policromadas, com as ligas de: chumbo-estanho, prata e chumbo, e chumbo-cobre-latão; o uso dos olhos de vidro e o uso dos elementos postiços como perucas e vestimentas.

Encontramos também dois trabalhos acadêmicos da Universidade Tecnológica Equinoccial (UTE) de Quito, Equador, que estudam a técnica da máscara de chumbo policromada e os artistas que a empregaram. Lucano Camacho (2010) fez uma abordagem biográfica do artista setecentista Bernardo de Legarda (? - 1773), o qual usou a tecnologia construtiva do molde com chumbo policromado na sua imaginária, sendo um dos grandes expoentes de seu tempo. Bernardo de Legarda trabalhou em vários ramos: escultura, imaginária, pintura, artes decorativas, como forjador e restaurador da sua época, possuiu sua própria oficina.

Uma das marcas da escultura originária de Quito é o refinamento dos rostos das imagens. Segundo a autora, a colocação das mascarillas está mais relacionada à busca por encarnes brilhantes e mais delicados, excepcionalmente elaborados para os rostos das Virgens. A imagem da Immaculada Legardiana ou Immaculada Apocalíptica, a Virgem de Quito, de 1734, localizada no nicho central do retábulo-mor da Igreja de São Francisco de Quito, possui tal aspecto: "O rosto fabricado com máscara de chumbo e olhos de vidro que proporcionam um realismo ao encarne?" (LUCANO CAMACHO, 2010, p. 59, tradução nossa). Outra imagem desse artista, a Assunção da Virgem é caracterizada por: "Policromia brilhante e belamente elaborada, finalmente, os olhos de vidro voltados ao céu e o modelado da máscara de chumbo amparados pelo encarne que denotam tranquilidade e misticismo no rosto jovem de 


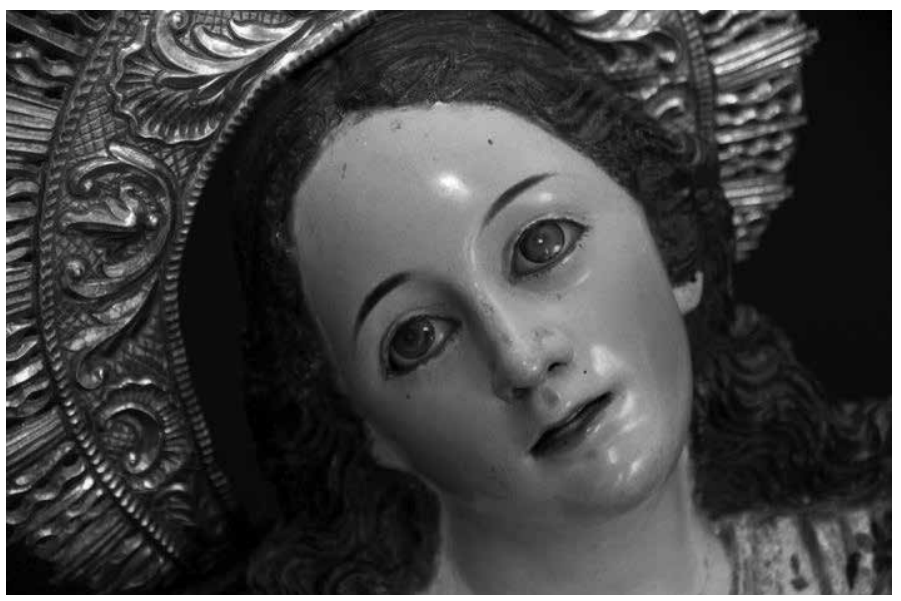

Maria $^{8 "}$ (LUCANO CAMACHO, 2010, p. 62, tradução nossa). Esta peça fica exposta no museu do convento de São Francisco em Quito no Equador.

Morález Vásconez (2006) realizou um estudo a respeito dos antecedentes e origens dessas máscaras metálicas em Quito. A escultura policromada colonial de Quito tem muita semelhança com a espanhola, já que esta é sua origem e influência, desse modo, como os outros autores mencionados, Morález Vásconez acredita que a origem das mascarillas metálicas é a Espanha. Posteriormente, para o abastecimento local e exportação das obras sacras, as mascarillas passaram a ser feitas na própria colônia por artesãos locais, a imaginária com máscara metálica foi amplamente aproveitada nas celebrações da Semana Santa. Tal autor encontrou no testamento de Bernardo de Legarda instrumentos para fazer moldes e colocar máscaras de chumbo.

Quanto à possível origem das máscaras metálicas foi possível estabelecer as seguintes hipóteses:

1. Originalmente vieram da Espanha para a América as estátuas ou esculturas completas, ou seja, com as máscaras de metal já colocadas e encaixadas ao resto da escultura vulto redondo.

2. Posteriormente, e talvez junto com as mesmas de vulto, $o$ peso e tamanho, entre outros, chegaram as máscaras de metal, rostos e até mesmo braços, pés, mãos, soltos, prontos para ser anexado pelos artífices locais. Eles ensamblaram especialmente nas imagens de vestir ou de roca que possibilitavam múltiplas devoções [...] especialmente para a Semana Santa, como a de Popayan, onde permanece ainda viva essa tradição.
Figura 1

Bernardo de Legarda - Asunción de la Virgen; detalhe de policromia, carnação e olhos de vidro; século XVIII; madeira policromada e dourada com máscara de chumbo; Museu de San Francisco, Quito, Equador; (LUCANO CAMACHO, 2010, p. 63). 
3. Hipótese pela qual nos posicionamos e que nos leva a pensar que depois de algum tempo as "máscaras de chumbo" foram feitas nas oficinas locais como a de Bernardo de Legarda e Arco, no Vice-Reino de Quito, de acordo com o seu testamento "que é encontrado bastão para o modelar e vazar." Instrumentos para fazer moldes e para colocação de chumbo" (MORÁLES VÁSCONEZ, 2006, p. 71-72, tradução nossa).

Além disso, o autor menciona experimentos realizados com o chumbo e outros componentes metálicos para a obtenção de mascarillas com uma textura perfeita, o que lhes proporcionava um melhor acabamento.

Na oficina de Legarda e Arco foram feitos todos os tipos de experimentos para obter, em perfeitas proporções, de várias misturas de estanho, chumbo e prata, que permitiriam a criação de máscaras de chumbo, fundidas com a textura ideal, prontas para receber as "encarnações e brilhos", que completariam o acabamento delicado do rosto de uma Virgem Maria com seus traços muito delicados e seu sorriso ainda de menina. Em seguida, eram adicionadas as decorações da indumentária e os detalhes como o cabelo que poderia cair anelados ou ondulados no rosto -, os cílios e sobrancelhas postiços ou dentes de porcelana. O toque final eram os brincos, diademas e todos os tipos de joias ${ }^{10}$ (MORÁLES VÁSCONEZ, 2006, p. 72, tradução nossa).

Lucano Camacho (2010) ressalta que essa técnica das mascarillas metálicas teve seu auge na Europa na época barroca, com o intuito de maior efeito comovedor, beleza deslumbrante do preciosismo dos acabamentos finais da policromia, sendo a máscara em moldes metálicos o melhor recurso para isso. De acordo com a autora, os procedimentos da confecção das máscaras metálicas eram realizados em etapas: a partir de um modelo feito de cera ou barro, muitos tinham feições andrógenas para servir a diferentes invocações de santos e santas; outros com traços muito delicados e cabelos com penteados que definiam o rostos para as virgens. A partir disso, tirava-se o molde e o contra-molde, e vertia-se o chumbo geralmente ligado a outro metal para proporcionar maior rigidez. No caso das cavidades oculares, era colocada uma proteção, ou após a secagem do metal aquela área era cortada para depois se agregar os olhos de vidro.

À vista disso, ainda conforme a autora, o processo de elaboração das máscaras metálicas pode ser resumido em três passos: 
1. Modelagem: o protótipo era feito em cera ou argila. No caso de Santos, Santos e Arcanjos a fisionomia deveria ser alegres, ou seja, sem qualquer característica predominante masculina nem feminina, com a finalidade de servirem à várias imagens; a caracterização específica de cada Santo era adquirida com o encarne adequado, com os atributos e vestimenta determinada. Havia outros moldes com detalhes incluindo barba, cabelos, traços muito delicados para as virgens com penteados ou cabelo ou cabelos ondulados, caindo para emoldurar o rosto. Uma vez ajustado o modelo e seca a argila, tomava-se o nome de molde, deste molde era tirado um contra-molde que poderia ser de madeira, gesso ou algo similar à vaselina no seu interior para evitar que a cera perdida aderisse ao barro.

2. Cera Perdida: este método consiste em derramar a cera diluída entre o molde e contra-molde selados hermeticamente, deixando apenas dois furos, um no topo da entrada de líquidos e outro inferior de saída dos mesmos; a cera se solidifica por dentro e momentaneamente ocupa o lugar do metal. Graças a essa técnica, é possível conseguir figuras em metal, sólidas e duráveis, com detalhes que seriam impossíveis de conseguir por outros meios.

3. Drenagem: finalmente pelo furo superior se derrama o metal líquido fundido a uma temperatura de $140^{\circ}$ a $200^{\circ} \mathrm{C}$. aproximadamente, este vai diluindo e retira a cera que sai pelo furo inferior; o metal ocupa o espaço dando espessura aos detalhes do molde configurando a máscara definitiva, uma vez que, esta esfrie e endureça. Era preciso ter cuidado para que o metal ocupasse todo o espaço sem deixar vazios. No caso das cavidades oculares, eram colocadas proteções ou também poderiam mais tarde abrir com uma lâmina deixando bordas bem polidas, da mesma maneira todas as rebarbas restantes são removidas e polidas a superfície para que se tenha uma textura tênue para que camadas de preparação tenham melhor aderência" (LUCANO CAMACHO, 2010, p. 87 - 88, tradução nossa).

Lucano Camacho diz que, geralmente, para as máscaras metálicas eram feitos olhos grandes e esses eram grudados com cera: "Uma vez definido o olhar, os olhos de vidro eram fixados com cera da Nicarágua, a qual era maleável e ao calor de suas mãos ganhava uma aderência resistente que com um pouco de pressão fixava os olhos à máscara metálica"12" (LUCANO CAMACHO, 2010, p. 90, tradução nossa). A montagem das mascarillas era feita depois de se colocar os olhos de vidro, em certos 
casos os olhos eram pintados diretamente no metal. A cabeça era esculpida somente com as formas dos cabelos, sem rosto, e era feito o corte vertical era realizado no sentido das fibras da madeira, na região superior da cabeça. Separava-se o rosto do crânio e, então, colocava a máscara com orifícios para ser afixada com os chamados cravos da Espanha. As bordas da madeira eram igualadas às da máscara e, em seguida, eram aplicadas muitas demãos de base de preparação. A base do metal era diferente da madeira, deveria ser levemente áspera para maior adesão à superfície lisa do metal, também era utilizado um adesivo à base de goma laca; tudo isso para o encarne do rosto apresentar um acabamento delicado e brilhante.

A montagem das máscaras era realizada após a colocação do vidro olhos, no entanto, em outro casos se policromava diretamente na máscara ao invés de abrir furos para colocar os olhos de vidro. Uma vez esculpida a cabeça apenas com as formas dos cabelos e sem esboçar o rosto, era colocado o formão na parte vertical superior da frente (onde começa o crescimento do cabelo) e seguindo as fibras da madeira com um golpe seco era separado o rosto de um único bloco até que parte baixa do queixo. No seu lugar, era colocada a máscara metálica que ia com três buracos na borda para ser fixada com os chamados cravos da Espanha. Finalmente as bordas da madeira eram igualadas e se procedia a aplicar as camadas de preparação em toda a peça para proporcionar uniformidade. É interessante notar que o tratamento prévio e aplicação da base de preparação era diferente do metal para a madeira; para melhor adesão deveria adicionar uma ligeira textura que era preparada com uma carga de serragem ou pedra-pomes, finamente moídas em uma mistura de 5 partes de álcool industrial para 1 goma laca aplicada por impregnação na superfície, em seguida, era aplicada a camada de a água e cola e finalmente a base de preparação quando seca era polida e recebia as camadas do encarne com acabamentos delicados e brilhantes ${ }^{13}$ (LUCANO CAMACHO, 2010, p. 88, tradução nossa).

Desse modo, as mascarillas, no início do século XVII, foram importadas, para depois serem fundidas na colônia, muitas eram reutilizadas e as que eram definitivas tinham a finalidade de se conseguir as encarnações, isto é, as policromias mais finas e delicadas para os rostos das imagens sacras. Estas eram figuras com carnação de acabamento de porcelana, brilhantes, e de grande naturalismo devido à suavidade da sua policromia. Se- 
gundo Morález Vásconez (2006), em virtude da ampla dramaticidade e teatralidade proporcionadas, as mascarillas levavam o fiel à contemplação e êxtase perante as imagens religiosas.

Portanto, existem duas vertentes a propósito da Escola de Quito de Imaginária do século XVIII e início do século XIX em relação ao uso das máscaras metálicas, ambas concordam que a origem dessa técnica ser espanhola e, como muitas outras, foram importadas e executadas pelos artífices nas colônias. Contanto, a primeira vertente, defende que a colocação das mascarillas foi um "atalho", um meio mais curto e rápido de abastecimento da demanda local e para a exportação de obras devocionais. Assim, elas foram peças confeccionadas em série, o que Kennedy-Troya (1998) denominou de uma "industrialização" dos processos produtivos, ou seja, não no sentido moderno do termo, com o uso de máquinas, mas, sim, a fatura de obras a partir de um mesmo modelo e em grande quantidade.

A outra vertente acredita que a utilização das máscaras de chumbo está vinculada à necessidade de um acabamento refinado e brilhante da policromia, especialmente para os rostos das Virgens, o que foi alcançado através das máscaras metálicas. Dessa maneira, constatamos que as máscaras em molde com chumbo e policromia foram mais um dos métodos setecentistas europeus transplantados para as colônias americanas, cujos artífices se inspiraram tanto na técnica quanto nos materiais. No que tange ao nosso objeto de estudo, as imagens do conjunto do Carmo de Ouro Preto dos Cristos da Paixão, são exemplos materiais dessa técnica aplicada no Brasil durante o século XVIII e XIX.

\section{O chumbo na escultura policromada e alguns ca- sos no Brasil: sinais em Minas Gerais e na Bahia}

Para o estudo do que cabe à fatura, materiais e técnicas da imaginária do século XVIII e do século XIX da Capitania de Minas, é necessário recorrer a pressupostos de como trabalhavam os mestres e oficiais nas oficinas mineiras, mas também, pesquisar como esse trabalho era feito em outras localidades do Brasil colônia, e, além disso, de que forma era produzido na própria metrópole e em outros países. As características materiais e técnicas das esculturas policromadas em madeira em Minas são de grande variedade e necessitam de estudos aprofundados na busca por fontes, referências bibliográficas e elementos comparativos. A noção dos materiais e procedimentos empregados na execução de uma escultura, baseada 
nos procedimentos utilizados pelos artífices, é importante para o conhecimento histórico, para a história da arte e para a preservação desse tipo de acervo.

Por conseguinte, no que concerne às referências nacionais sobre a técnica da máscara de chumbo policromada, como foi abordado, temos somente alusões sobre os Cristos da Paixão do Carmo de Ouro Preto. Assim, podemos citar inicialmente a pesquisa de Campos (2000) a respeito dos monumentos religiosos de Ouro Preto, a qual ao tratar da procissão do Triunfo e da imaginária da Ordem Terceira do Carmo comenta que as imagens dos Cristos que saíam no cortejo possuem as cabeças em chumbo, o que na verdade seria somente a região da face, compondo uma máscara metálica.

No Brasil Colônia, a Procissão do Triunfo feita no Domingo de Ramos, era exclusiva da Ordem Terceira do Carmo. Nela eram conduzidos em andores Sete Passos da Paixão de Cristo. Tais imagens do acervo carmelitano de Vila Rica são muito diferentes por apresentarem a cabeça em chumbo (CAMPOS, 200o, p. 32).

Outra menção aos Cristos da Paixão do Carmo de Ouro Preto e sobre a procedência da sua técnica foi encontrada na publicação de Oliveira (2005), relacionada à Escola de Imaginária Mineira e suas Particularidades, em que a autora levanta a possibilidade das imagens dos Cristos com a face de chumbo não terem sido feitas em Minas Gerais, seriam provavelmente originárias do Rio de Janeiro ou de Portugal.

A igreja da Ordem Terceira do Carmo, de Ouro Preto, apresenta, ainda hoje, a série completa de imagens dos Passos nos retábulos da nave, todas esculpidas por inteiro, mas com a particularidade única de as faces serem de chumbo policromado, o que pode significar que tenham sido importadas do Rio de Janeiro ou Portugal (OLIVEIRA, 2005, p. 24).

Cremos que a autora propõe essas duas hipóteses fundamentadas em questões da história e do desenvolvimento da imaginária devocional colonial brasileira. Em um primeiro momento, sobre as imagens dos Cristos serem provenientes de Portugal, como foi visto, essa técnica era comum nos países ibéricos e principalmente na Espanha. Ademais, era usual a importação de artistas e de imagens portuguesas, cujas partes mais importantes como: cabeças, mãos, pés, eram usadas especialmente para as imagens de vestir da tipologia de roca, 
eram esculpidas na metrópole enquanto que a estrutura e a montagem eram feitas na colônia. Tal fato foi recorrente nas imagens mais antigas e de caráter erudito, que saíam nas procissões da Semana Santa, como as imagens de Nossa Senhora das Dores e as dos Cristos da Paixão.

Em relação a essas imagens serem originárias da cidade do Rio de Janeiro, tal hipótese sucede provavelmente porque na antiga capital do vice-reinado português, havia uma casa de fundição, a Casa do Trem, antigo arsenal de guerra, que foi construída em 1762. Nesse ambiente, coube a Valentim da Fonseca e Silva, o mestre Valentim, inaugurar no Brasil a arte da cultura em metal fundido. Entre os anos de 1779 e 1783, foram fundidos no Trem, por mestre Valentim, os dois jacarés em bronze da fonte dos amores, localizada no Passeio Público. Essas foram as primeiras esculturas fundidas naquele local, sendo aquela a única repartição da época com forjas e outros elementos capazes de efetuar tais serviços. Implica-se que não necessariamente mestre Valentim tenha fundido as máscaras naquele local, mas que talvez algum outro artífice, nativo ou reinol, poderia as ter executado.

Ainda, no que concerne às mascarillas, temos a referência de Coelho (2005) acerca dos diferentes tipos de materiais empregados nos suportes das esculturas policromadas em madeira. A autora trata das diferentes técnicas em imagens que se utilizaram além da madeira, mais um material como suporte, no caso o chumbo, sendo esses casos inusitados em Minas Gerais. A exemplo disso, a autora menciona as mãos do São Jorge do Museu da Inconfidência, atribuída a Aleijadinho, bem como os Cristos da Paixão do Carmo de Ouro Preto, os quais são objeto dessa pesquisa.

Em Minas Gerais, há, também, imagens feitas em mais de um material: o São Jorge do Aleijadinho do Museu da Inconfidência, em Ouro Preto, é em madeira, mas tem as mãos em chumbo; todos os Cristos dos altares laterais da Igreja de Nossa Senhora do Carmo, em Ouro Preto, têm a face em chumbo; como as mascarillas usadas nos países andinos (COELHO, 2005, p. 235).

A partir disso, pesquisamos alusões a respeito de uma imaginária do século XVIII e início do século XIX em chumbo na região das Minas Gerais. Como ponto de partida, temos o São Jorge citado por Coelho (2005) acima. De acordo com a sua ficha de catalogação, essa escultura é da segunda metade do 
século XVIII, sendo de madeira cedro, policromada e dourada. A imagem de São Jorge foi adquirida pelo Museu da Inconfidência de Ouro Preto, local em que se encontra atualmente, por transferência da Igreja Matriz de Nossa Senhora do Pilar de Ouro Preto, entre os anos de 1940-1946.

Na descrição formal dessa ficha, foi relatado que seu atributo, a lança, tem ponta em chumbo e seria a original da imagem: "A ponta da lança é de chumbo fundido" (FICHA DE CATALOGAÇÃO, 1999, p. 1). No antigo arrolamento de Bens Móveis do IPHAN/SPHAN/FNPM - Grupo I e II de Museus e Casas Históricas de Minas Gerais, elaborado por Maria José de Assunção da Cunha e equipe, realizado entre os anos de 1979 e 1981, na relação de objetos localizados no museu da Inconfidência se tem a informação: "Mãos de chumbo" (FICHA DE CATALOGAÇÃO, 1999, p. 2). No entanto, no ano de 2009, foi feita a restauração dessa peça e foi encontrada a seguinte verificação: "Em 08/o1/2009: Objeto em processo de restauração. Informações complementares, quanto à descrição física: Mão direita de chumbo fundido, com carnação. Mão esquerda em madeira talhada, com carnação" (FICHA DE CATALOGAÇÃO, 1999, p. 1).

Assim, essa escultura possui somente a mão direita feita em chumbo, essa é a mão que segura a lança que também possui a ponta em chumbo fundido, sendo o restante da talha da imagem em madeira. Esse São Jorge é outro exemplo de escultura confeccionada com diferentes tipos de suporte na região de Minas, provavelmente a mesma foi feita no Brasil, já que foi atribuída a Aleijadinho. O São Jorge, como os Cristos da Paixão, apresenta madeira e chumbo policromados na sua estruturação formal.

Outro exemplar de uma imaginária em chumbo em Minas também está presente no trabalho de Coelho (2005), a autora traz um crucifixo com a imagem de Cristo feita toda em chumbo fundido policromado, e a cruz em madeira dourada, datado do final do século XVIII, da Igreja Matriz de Caeté.

Temos ainda, as imagens em miniatura do acervo do $\mathrm{Mu}-$ seu do Oratório de Ouro Preto: uma Nossa Senhora da Conceição, um Santo Antônio, e um Crucificado. De acordo com os dados gerais das fichas desses objetos, todas as imagens foram adquiridas em 29 de outubro de 1998 . Foram classificadas como escultura em miniatura de fatura popular, procedentes de Minas Gerais. A imagem de Nossa Senhora da Conceição é datada do século XIX e foi confeccionada em chumbo fundido apresentando resquícios de policromia. As esculturas de Santo Antônio e a do Cristo Crucificado foram feitas em chumbo, 

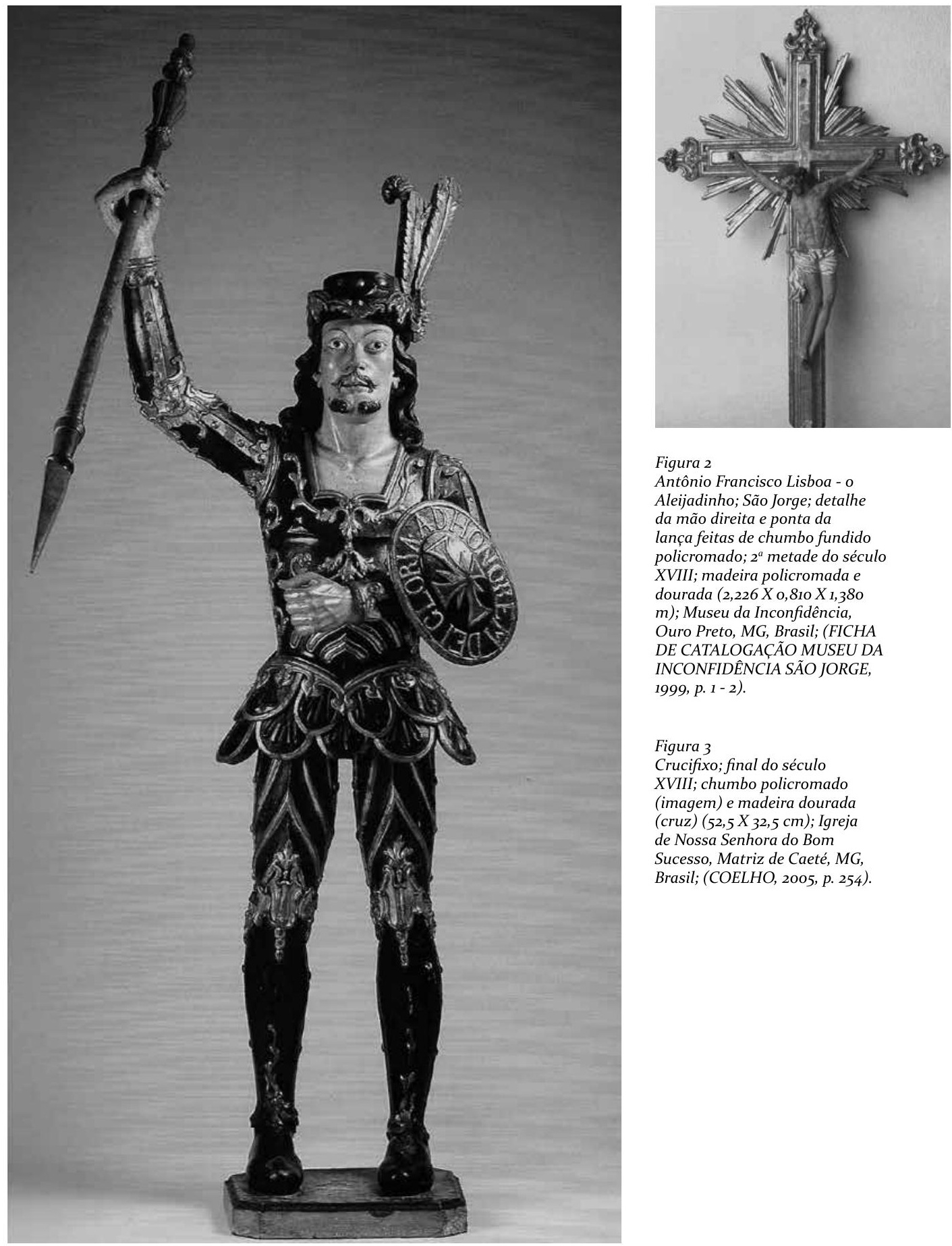

Figura 2

Antônio Francisco Lisboa - o Aleijadinho; São Jorge; detalhe da mão direita e ponta da lança feitas de chumbo fundido policromado; $2^{a}$ metade do século XVIII; madeira policromada e dourada $\left(2,226 X_{0}, 810 X_{1,380}\right.$ m); Museu da Inconfidência, Ouro Preto, MG, Brasil; (FICHA DE CATALOGAÇ̃̃O MUSEU DA INCONFIDÊNCIA SÃO JORGE, 1999, p. 1 - 2).

\section{Figura 3}

Crucifixo; final do século XVIII; chumbo policromado (imagem) e madeira dourada (cruz) (52,5 $\left.X_{32,5} \mathrm{~cm}\right)$; Igreja de Nossa Senhora do Bom Sucesso, Matriz de Caeté, MG, Brasil; (COELHO, 2005, p. 254). 


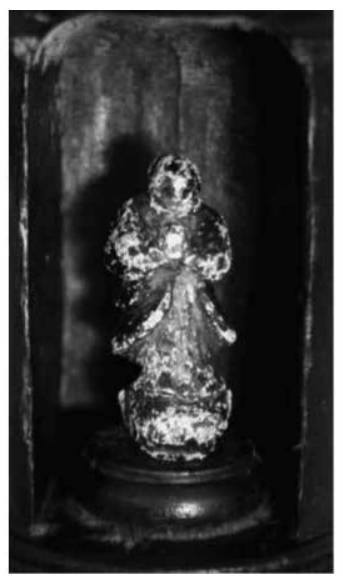

Figura 4

Esculturas em miniatura em chumbo fundido: Nossa Senhora da Conceição, século XIX; Santo Antônio $\left(12,5 X_{5,0} X_{4}, 0 \mathrm{~cm}\right)$, final do século XIX e início do $X X$; Crucificado $\left(6,0 X_{1,5} X_{1,5}\right.$ $\mathrm{cm})$, início do século $X X$; chumbo

fundido; Museu do Oratório, Ouro Preto, MG, Brasil; (FICHA DO OBJETO, MUSEU DO ORATÓRIO, 1999).

Figura 5

Frei Agostinho da Piedade; busto-relicário de Santa Luzia; por volta de 1630; cabeça moldada em chumbo e corpo de prata batida (51 cm); Museu de Arte Sacra da UFBA, Salvador, BA, Brasil; (SILVA-NIGRA, 1971, p. 37 apud DANNEMANN, 2003, p. 38).
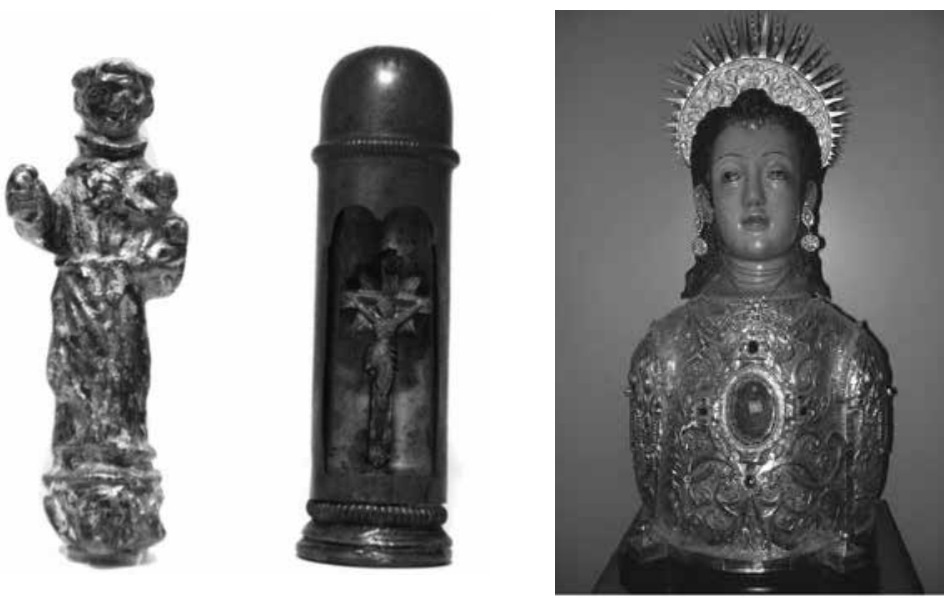

porém sem policromia, a primeira é do final do século XIX e início do século XX, e a segunda sendo do século XX, é parte integrante de um oratório bala feito em latão fundido.

Com esses vestígios de uma imaginária mineira feita totalmente ou apresentando algumas partes em chumbo, com ou sem policromia, procurou-se dados sobre a história das primeiras casas de fundição da antiga Vila Rica. Essas seriam possíveis lugares com elementos necessários, como forjas e instrumentos, para a fundição de imagens em chumbo. Segundo Silva (2007), na Capitania de Minas para se evitar o contrabando de ouro e outros minérios da Coroa portuguesa, criou-se em 1702 a Intendência das Minas, encarregada de fiscalizar a atividade mineradora e de cobrar impostos. Posteriormente, foi criado o Quinto para facilitar o imposto sobre a atividade mineradora e também a Casa de Fundição, onde o ouro era fundido em barras e entregue ao minerado já reduzido e com o selo real. As Casas de Fundição foram instituídas pela Coroa com a entrada em vigor da Lei de 11 de fevereiro de 1719, que previa o funcionamento dessas Casas a partir de 23 de julho de 1720, para a tributação do ouro.

Em Ouro Preto, a Casa de Fundição, conhecida como Casa dos Contos, foi construída entre os anos de 1782-1784, a qual originalmente foi residência particular de um alto funcionário da administração portuguesa, pertencente a João Rodrigues Macedo, homem de singular fortuna, arrematante de contratos e arrecadação de dízimos e entradas. Nessa casa é ainda possível ver nos fundos, a gigante chaminé da fundição do ouro (VASCONCELLOS, 1934 apud DRUMMOND, 2011). 
Não podemos afirmar que qualquer uma dessas imagens em chumbo, ou mesmo as máscaras dos Cristos da Paixão, foram fundidas lá. Contudo, foi um local de cunhar moedas e barras de ouro, ofício que exigia um conhecimento específico e artesanal e que poderia abrir possibilidades para outras artes.

Em outras regiões do Brasil, como a Bahia, deparamos com o busto-relicário de Santa Luzia, de autoria do monge beneditino Frei Agostinho da Piedade, século XVII, proveniente da antiga Igreja do Colégio de Jesus de Salvador. O busto-relicário de Santa Luzia tem a cabeça em chumbo policromado e a coroa e o corpo revestidos de prata repuxada e cinzelada, busto que ainda possui a relíquia da mártir Luzia protegida detrás do vidro do estojo (DANNEMANN, 2003). Esta imagem encontra-se atualmente no Museu de Arte Sacra da Universidade Federal da Bahia.

Então, com a pesquisa e análise dessas referências internacionais e nacionais sobre a máscara em chumbo policromado, buscamos pressupostos relacionados à sua origem, época, uso e forma de aplicação, bem como indícios da imaginária em chumbo no Brasil. Com isso, pretendeu-se fazer um estudo comparativo entre os dados acima coletados e as esculturas do Cristo da Paixão do Carmo de Ouro Preto, a fim de entendermos ainda mais a completude dessas obras. Todavia, na sequência, foi feita uma análise formal de equivalência entre as máscaras dos Cristos.

\section{As máscaras de chumbo: a contingência das esculturas policromadas em madeira dos Cristos da Paixão do Carmo de Ouro Preto}

Todas as esculturas dos Cristos da Paixão têm a face em molde de chumbo policromado. Acreditamos que foi utilizado o mesmo molde para a confecção das máscaras, já que todas as imagens possuem a mesma fisionomia e representam o mesmo personagem religioso, Jesus Cristo. Com o registro fotográfico observou-se a delimitação entre a máscara de chumbo e o crânio em madeira. Dessa maneira, constatamos traços semelhantes de: nariz, boca, barba, o detalhe da sobrancelha em relevo, os quais foram notados em todas as faces dos Cristos.

Verificamos também, na região superior do alto da cabeça de cada Cristo da Paixão, a divisão entre a máscara em chumbo e o crânio de madeira, bem como a divisão nas laterais da face e a mesma separação por detrás da barba. No entanto, a talha da orelha e o formato de cada crânio são diferentes entre 

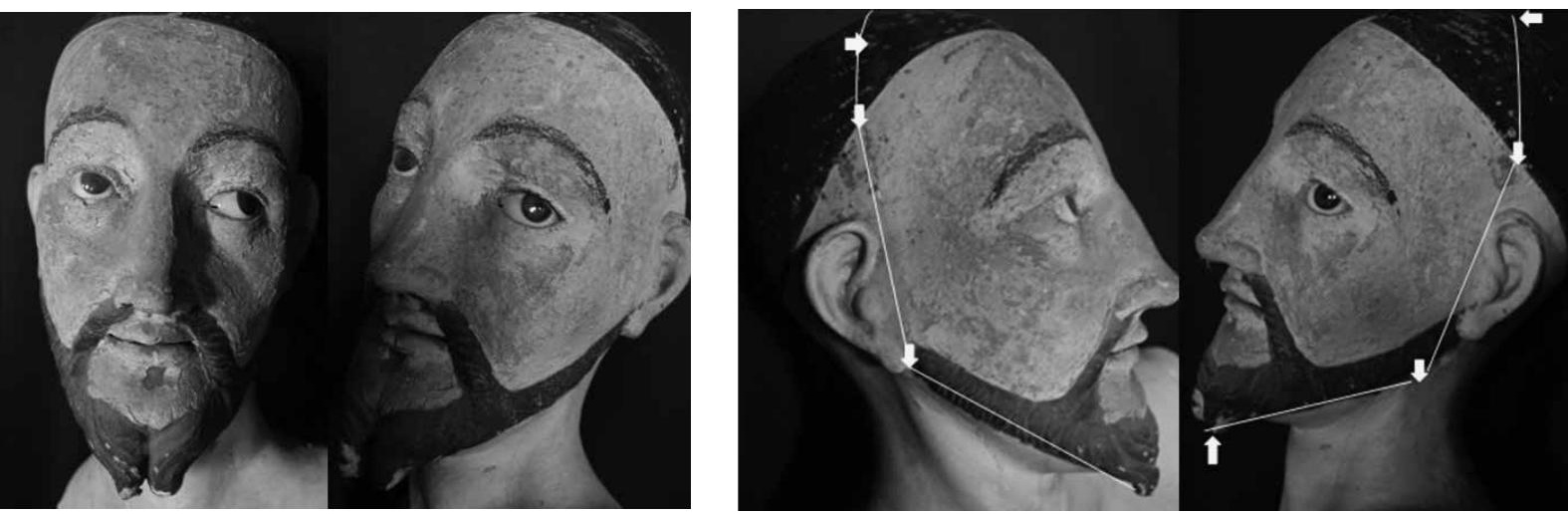

Figura 6

Cristo no Horto; detalhe frente e de perfil; século XVIII; escultura em madeira com máscara de chumbo policromadas $(1,22 X$ $70 X 33 \mathrm{~cm}$ ); Igreja da Ordem Terceira de Nossa Senhora do Carmo de Ouro Preto, MG, Brasil; Lia Sipaúba 03/04/2013.

Figura 7

Cristo no Horto; detalhe lado direito e lado esquerdo; delimitação da máscara; século XVIII; escultura em madeira com máscara de chumbo policromadas; Igreja da Ordem Terceira de Nossa Senhora do Carmo de Ouro Preto, MG, Brasil; Lia Sipaúba 03/04/2013.

Figura 8
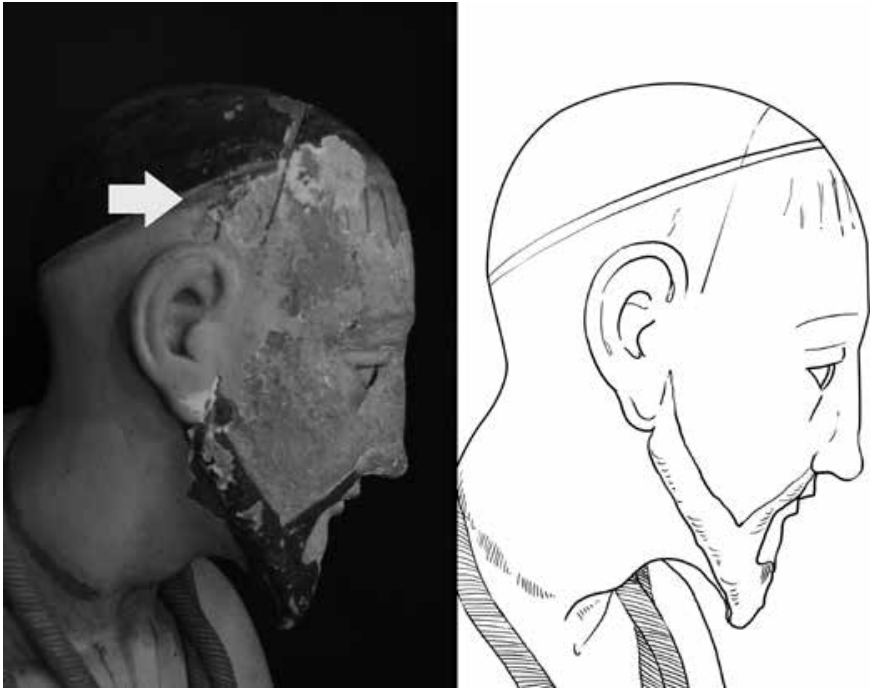

Cristo da Flagelação; detalhe lateral direita; desenho gráfico; século XVIII; escultura em madeira com máscara de chumbo policromadas $\left(1,65 X_{50} X_{54}\right.$ cm); Igreja da Ordem Terceira

de Nossa Senhora do Carmo de Ouro Preto, MG, Brasil; Lia Sipaúba 01/04/2013.

os Cristos, possivelmente executados por escultores distintos. Isto posto, foi realizado o desenho gráfico do Cristo da Flagelação para a melhor visualização da separação entre a máscara em metal e o crânio em madeira.

Os olhos das imagens são de vidro, parece-nos que esses possuem ao seu redor uma massa, provavelmente a mesma da base de preparação, para fazer o formato das pálpebras. Isso foi notado porque essa é a região que apresenta menos desprendimento da policromia, sendo a área em chumbo a que mostrou maior perda da camada pictórica em todas as esculturas.

Segundo Coelho (2005), as imagens podem ter os olhos esculpidos e pintados, ou de vidro, na segunda metade do século 

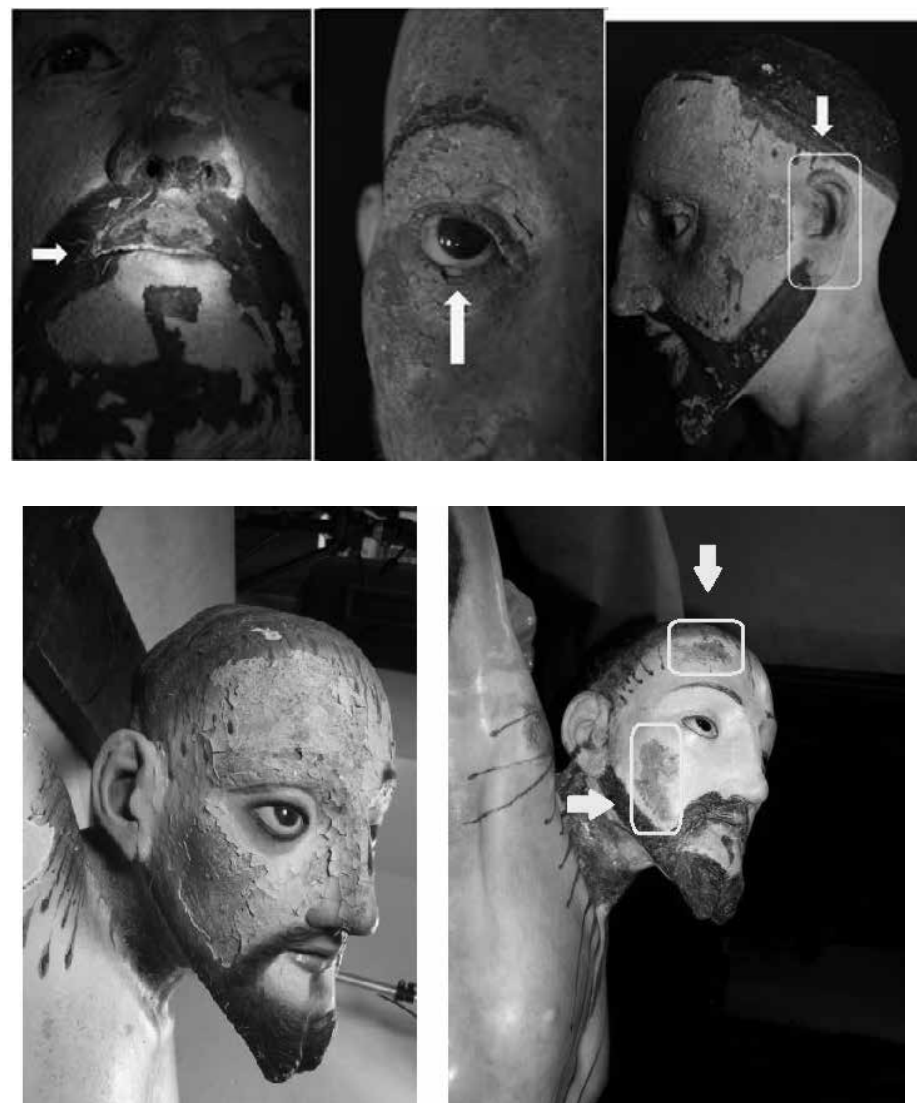

XVIII, os olhos de vidro são encontrados na maioria das imagens, muitos foram importados de Portugal. Para a colocação dos olhos de vidro, após o término da talha, o escultor abria a cabeça da figura no sentido vertical, da direção das fibras, entre a face e o crânio, escavava internamente a região da cavidade ocular e colocava os olhos, e os prendia com uma cera.

De acordo com Lucano Camacho (2010), o procedimento de colocação de olhos de vidro com a máscara metálica era bem semelhante, separava a face do crânio e encaixava os olhos com cera. O que diferenciava era que a parte da face em madeira não era esculpida, mas, sim, descartada, e agregava em seu lugar a mascarilla metálica para depois policromar a escultura.

Outra questão interessante é que foi possível notar na face do Cristo com a Cruz às Costas, na área da boca, devido à perda de repintura e policromia, o detalhe do desenho dos dentes no
Figura 9

Cristo com Cruz às Costas $(1,87$ $\left.X 6_{3} X_{76} \mathrm{~cm}\right)$, Cristo Coroado de Espinhos $\left(1,31 X_{41} X_{51} \mathrm{~cm}\right)$ e Cristo Ecce Homo $\left(1,69 X_{41} X_{40}\right.$ $\mathrm{cm})$; detalhe dos dentes, olhos de vidro e talha da orelha; século XVIII; escultura em madeira com máscara de chumbo policromadas; Igreja da Ordem Terceira de Nossa Senhora do Carmo de Ouro Preto, MG, Brasil; Lia Sipaúba 04/2013.

Figura 10

Cristo Crucificado; antes e depois da restauração e detalhe das janelas com chumbo amostra; século XVIII; escultura em madeira com máscara de chumbo policromadas (1,84X $\left.1,25 X_{32} \mathrm{~cm}\right)$; Igreja da Ordem Terceira de Nossa Senhora do Carmo de Ouro Preto, MG, Brasil; (GRUPO OFICINA DO RESTAURO, 2010, p. 8). 
metal. Tal minúcia também foi observada no Cristo Crucificado, imagem que foi restaurada em 2009-2010 pelo Grupo Oficina do Restauro, sendo realizada a remoção das repinturas e cuja restauração deixou janelas com o chumbo à amostra.

Dessa forma, com esse registro fotográfico foram notadas as particularidades e principais aspectos das máscaras metálicas dos Cristos da Paixão, moldadas a partir de um único modelo. Sendo assim, as máscaras metálicas seriam mais um dos artifícios e engenhosidades contemplados pelo teatro místico barroco. É de fundamental importância a averiguação técni$\mathrm{ca} /$ material aplicada ao conhecimento da escultura policromada em madeira. Este tipo investigação requer uma pesquisa histórica da obra de arte a partir de uma perspectiva desse objeto como testemunho documental de uma época concreta que é necessário preservar e transmitir ao futuro.

\section{Considerações finais}

Este artigo, como seu próprio título indica, foi a tentativa de contribuir para o estudo das esculturas devocionais brasileiras, a partir de uma conjuntura particular, o contexto histórico e elementos formativos das imagens dos Cristos da Paixão da Igreja da Ordem Terceira de Nossa Senhora do Carmo de Ouro Preto (MG), no desenrolar do século XVIII ao século XIX. Nessa perspectiva, foi nosso objetivo principal de estudo a técnica da escultura em madeira com máscaras de chumbo policromadas. Por consequência, tais imagens foram itens de uma investigação através de uma abordagem histórica, artística, material e técnica. Com efeito, foi traçado um panorama de hipóteses para preencher algumas lacunas da história dos Cristos.

A partir da investigação histórica da técnica da escultura em madeira com máscara de chumbo policromadas, encontramos alguns dados que suprem brechas a respeito das imagens dos Cristos da Paixão. Foi constatado que o uso de máscaras metálicas em esculturas devocionais é originário da Espanha, durante o século XVII e XVIII, sendo estas máscaras importadas pelas colônias americanas, para posteriormente serem confeccionadas por artistas locais ou reinóis radicados aqui. A técnica construtiva da face, máscara, em molde com chumbo e policromia tinha a função de definir as feições iconográficas, em que representa um mesmo personagem, como Jesus Cristo, ou apresentava fisionomia andrógena podendo compor santos e santas.

Os estudos relacionados à Escola de Quito de Imaginária 
apresentam duas vertentes relacionadas à utilização dessas máscaras metálicas. A primeira argumenta que o uso das mascarillas foi uma espécie de "industrialização" da manipulação dos processos produtivos, em que os artistas criaram "atalhos" por meio de uma produção em série e em grande quantidade, para suprir a demanda local e a externa, sendo as mascarillas um desses recursos. A outra vertente afirma que as mascarillas seriam uma solução encontrada pelos artífices para possibilitar um acabamento delicado e brilhante no rosto das imagens, especialmente em Virgens. No entanto, ambas vertentes defendem que as máscaras metálicas proporcionavam uma policromia extraordinária às imagens, desse modo, não é uma técnica rudimentar, mas sim, que visava acabamentos perfeitos e de um realismo impressionante.

Buscando por referências nacionais relacionadas às mascarillas, encontramos somente alguns estudos que mencionam exatamente o nosso objeto em análise, os Cristos da Paixão do Carmo de Ouro Preto, visto que não podemos afirmar ainda que existem imagens com essa técnica em Minas ou em outras regiões do Brasil. Assim, procuramos por indícios de uma imaginária mineira feita totalmente ou possuindo parte em chumbo, e possíveis lugares de sua fabricação, como as Casas de Fundição, implantadas na Capitania de Minas no início dos setecentos.

Em Ouro Preto encontramos a imagem de São Jorge, atribuída a Aleijadinho, com a mão direita em chumbo policromado, uma imagem de Cristo Crucificado todo em chumbo policromado, no município de Caeté, ambas do século XVIII, e as imagens em miniatura do acervo do Museu do Oratório, do século XIX e XX. Em Salvador, na Bahia, localizamos um busto-relicário do Frei Agostinho da Piedade com a cabeça em chumbo policromado e o corpo em prata cinzelada e repuxada. Estas obras são indicativos para uma pesquisa mais aprofundada sobre o chumbo na imaginária devocional brasileira.

Em vista desses aspectos analisados, a hipótese que levantamos é que essas mascarillas foram importadas e as esculturas montadas aqui na colônia, para que assim as imagens dos Cristos saíssem em cortejo, como era tradição a iconografia da Paixão e a procissão do Triunfo entre os terceiros carmelitas. Acreditamos que o uso das máscaras de chumbo visava a um acabamento impressionante da policromia, apesar disso não poder ser notado hoje devido às intervenções e deterioração do acervo, foi o artifício utilizado na busca de um realismo que comovesse os fiéis. 
Portanto, o estudo da escultura em madeira policromada é amplo e interdisciplinar, esse tipo de investigação ajuda na compreensão e preservação do patrimônio brasileiro. O presente trabalho resulta da pesquisa e interpretação de dados de outros estudos a respeito do tema e das fontes primárias coletadas in loco. É sabido que estudo a respeito da máscara de chumbo policromada é inédito no Brasil, cremos que essas informações são apenas subsídios para pesquisas posteriores entre outras regiões do Brasil e sua relação com as colônias americanas e as metrópoles ibéricas ao longo do século XVIII.

\section{NOTAS}

1. Texto original em espanhol.

2. Texto original em espanhol.

3. Texto original em espanhol.

4. Texto original em espanhol.

5. Texto original em espanhol.

6. Texto original em espanhol.

7. Texto original em espanhol.

8. Texto original em espanhol.

9. Texto original em espanhol.

10. Texto original em espanhol.

11. Texto original em espanhol.

12. Texto original em espanhol.

13. Texto original em espanhol.

\section{Referências}

BRUSADIN, L. S. P. Os Cristos da Paixão da Ordem Terceira do Carmo de Ouro Preto (MG). 26o f. Dissertação (Mestrado em Artes) - Escola de Belas Artes, Universidade Federal de Minas Gerais, Belo Horizonte, 2014.

CAMPOS, A. A. Roteiro Sagrado: monumentos religiosos de Ouro Preto. Belo Horizonte: Tratos Culturais/Editora Francisco Inácio Peixoto, 2000.

COELHO, B. (Org.). Devoção e Arte: imaginária religiosa em Minas Gerais. São Paulo: Edusp, 2005.

DANNEMANN, J. C. S. Coleção de Bustos-Relicários da Antiga 
Igreja do Colégio de Jesus de Salvador da Bahia: Preservação de 30 Esculturas do Século XVII. Dissertação (Mestrado em Artes Visuais) 2003 - Escola de Belas Artes da Universidade Federal de Minas Gerais (UFMG), 2003.

GALLEGOS DE DANOSO. M. El Desarrolo de la Escultura en la Escuela Quiteña. Encuentros. Conferencia del Centro Cultural del BID, Banco Interamericano de Desarrolo en Washington,D. C., 5 de Octubre, 1994.

GRUPO OFICINA DO RESTAURO. Relatório da Restauração do Cristo do Retábulo Consistório da Igreja de Nossa senhora do Carmo Ouro Preto/MG. Período Correspondente a Maio e Dezembro de 2009. Belo Horizonte, 22 de abril de 2010, Rosangela Reis Costa.

KENNEDY-TROYA, A. Circuitos Artisticos Interregionales de Quito a Chile. Siglos XVIII y XIX. Historia, 1998 (vol. 31). . (Ed.). Arte de la Real Audiencia de Quito, siglos XVII-XIX. España: Editorial Nerea, 2002. . Arte y Artistas Quiteños de Expostación. In: VVAA. Arte quiteño más Allá de Quito. Memorias del Simposio, Quito, FONSAL, 2009.

LUCANO CAMACHO, M. F. Bernardo de Legarda: una mirada cientifica a su obra Escultorica. 2010. Tesis Previa a la Obtención del Título de Licenciada en Restauración y Museología - Facultad de Arquitectura Artes y Diseño Universidad Tecnológica Equinoccial (UTE), Quito, Ecuador, 2010.

MORAES, L. S. P. O dinamismo cultural na capital do vice-reinado Português (1763-180o): A representatividade e o legado de Mestre Valentim. In: História e-História. 12/10/2011, ISSN 1807-1783.

MORÁLES VÁSCONEZ, J. C. Técnica y materiales empleados en la policromía de la escultura colonial quiteña y su aplicación con miras a la restauración. 2006. Tesis Previa a la Obtención del Título de Licenciado en Restauración y Museología - Facultad de Arquitectura, Artes y Diseño, Escuela de Restauración y Museología Universidad Tecnológica Equinoccial (UTE) Quito, Ecuador, 2006.

MORÁN PROAÑO, N. Guión Unificado Quito Español. Texto guia para actualización a miembros de la red metropolitana de museos de Quito. Quito: Arte y Cultura, s/d.

MUSEU DO ORATÓRIO. Instituto Cultural Flávio Gutierrez. Ficha do Objeto - Dados Gerais. Escritura de Doação, 9-Oratório bala, Ângela Gutierrez. Escritura Pública de Doação, com Reserva de Usufruto. Serviço Notarial do $8^{\circ}$ 
Ofício de Belo Horizonte Felício dos Santos. 29/10/1998. Inventário Coleção Ângela Gutierrez/Museu do Oratório. Inventário inicial do acervo feito por Cristina Ávila e Rosângela Reis Costa, 18/o1/1997.

MUSEU DO ORATÓRIO. Instituto Cultural Flávio Gutierrez. Ficha do Objeto - Dados Gerais. Escritura de Doação, 4-Oratório bala, Ângela Gutierrez. Escritura Pública de Doação, com Reserva de Usufruto. Serviço Notarial do $8^{\circ}$ Ofício de Belo Horizonte Felício dos Santos. 29/10/1998.

MUSEU DO ORATÓRIO. Instituto Cultural Flávio Gutierrez. Ficha do Objeto - Dados Gerais. Escritura de Doação, 73-Oratório afro-brasileiro, Ângela Gutierrez. Escritura Pública de Doação, com Reserva de Usufruto. Serviço Notarial do $8^{\circ}$ Ofício de Belo Horizonte Felício dos Santos. 29/10/1998. Inventário Coleção Ângela Gutierrez/Museu do Oratório. Inventário inicial do acervo feito por Cristina Ávila e Rosângela Reis Costa, o8/o9/1997.

MUSEU DA INCONFIDÊNCIA (IBRAM) - Ouro Preto Minas, Gerais, SCAM - Sistema de Controle do Acervo Museológico, Ficha de Catalogação, № Inventário 362, data de catalogação 01/03/1999 e data da revisão: 24/06/2004.

OLIVEIRA, M. A. R. A escola mineira de imaginária e suas particularidades. In: COELHO, B. (Org.). Devoção e Arte: imaginária religiosa em Minas Gerais. São Paulo: Edusp, 2005.

QUITES, M. R. E. Imaginária processional na Semana Santa em Minas Gerais. Estudo realizado nas cidades de Santa Bárbara, Catas Altas, Santa Luzia e Sabará. 1997.Dissertação de Mestrado (Mestrado em Artes) - Centro de Conservação e Restauração da Escola de Belas Artes da Universidade Federal de Minas Gerais (UFMG), 1997.

. Imagem de vestir: revisão de conceitos através de estudo comparativo entre as Ordens Terceiras Franciscanas no Brasil. 2006. Tese (Doutorado em História) - Departamento de História do Instituto de Filosofia e Ciências Humanas da Universidade Estadual de Campinas (UNICAMP), 2006.

SERCK-DEWAIDE, M. Bref historique de l'évolution dês traitements dês sculptures. Bulletin do IRPA - Institut Royal Du Patrimoine Artistique. Bruxeles, 1999/1998, n. 27. Tradução B. Coelho. In: Boletim do CEIB - Centro de Estudos da Imaginária brasileira, v. 9, n. 31. jul. 2005.

SILVA, M. B. N. A Coroa e a remuneração dos vassalos. In: RESENDE, M. E. L.; VILLALTA, L. C. História das Minas Gerais - As Minas Setecentistas. Belo Horizonte: Autênti- 
ca; Companhia do Tempo, 2007 (vol. 1).

VALLIN, R. Agustín de Chinchilla Cañizares, maestro escultor en yeso. Boletín Cultural y Bibliográfico, Biblioteca Luis Ángel Arango del Banco de la República, Colombia - Bogotá, v. XXIV, n. 12, 1987.

VASCONCELOS, D. As obras de arte. In: DRUMMOND, M. F. S. I. (Org.) Ouro Preto, cidade em três séculos. Bicentenário de Ouro Preto; Memória Histórica (1711-1911). Ouro Preto: Liberdade, 2011.

Recebido em: 16/04/15

Aceito em: 16/12/15

\section{LIA SIPAÚBA PROENÇA BRUSADIN}

liaunesp@hotmail.com

É graduada em bacharelado e licenciatura em História pela Universidade Estadual Paulista (UNESP), Especialista em Cultura e Arte Barroca pela Universidade Federal de Ouro Preto (UFOP), Mestre e Doutoranda em Artes pela Universidade Federal de Minas Gerais (UFMG).

\section{MARIA REGINA EMERY QUITES}

É graduada em bacharelado e licenciatura em Artes Plásticas, Especialista em Conservação Restauração de Bens Culturais e Mestre pela Universidade Federal de Minas Gerais (UFMG), Doutora em História pela Universidade Estadual de Campinas (UNICAMP). Professora do Departamento de Artes Plásticas e do Programa de Pós-Graduação em Artes da Escola de Belas Artes da UFMG. 